\section{Crowdsourcing of Local Spatial and Historical Knowledge}

GI_Forum 2016, Vol.2 Page: 109-122 Full Paper Corresponding Author: daniel.vrbik@tul.cz

DOI:

10.1553/giscience2016_02_s109

\title{
Daniel Vrbik
}

Technical University of Liberec, Czech Republic

\begin{abstract}
Crowdsourcing and volunteered geographical information (VGI) have proven to be popular methods in many citizen science projects, but using the knowledge of the crowd in data mining of old maps is still rare. This paper presents the project "Stories of Places", the aim of which is to collect spatial and subjective data about peaks based on a particular map of north Bohemia from 1927 using the author's own web map application. The quality control of data is conducted by participants themselves: anyone involved in the project could validate the data. The results of the data collection are explored from statistical and spatial points of view as well as by the volunteers. Involved in the project were 19 participants from both inside and outside the region studied, proving that the public is able to analyse an old map. The results also showed differences in the way volunteers work, indicating that volunteers from the region are more suitable for collecting qualitative data. The results of the project from the perspective of the participants as well as the author are discussed in the conclusion.
\end{abstract}

\section{Keywords:}

public participation, old maps, data mining, VGl, citizen science

\section{Indroduction}

In places where political development has led to many changes (in the population structure, land use, the perception of landscapes, etc.), old maps and plans present a valuable source of information for names, local monuments, land use, etc. The information can be used in many different fields of study, such as urban planning, archaeology, linguistics and cultural heritage, among others. This has been proved by several studies in the Czech Republic (Brůna et al., 2014) and abroad (Cousins, 2001; Domaas, 2007) which have focused on the history of a place both. Such old maps could also help in the rebuilding of "local knowledge" as a substitute for people's knowledge being transferred from one generation to another.

Information obtained from or through the use of an old map could include two types: specific localized information displayed on the map itself (lost settlements, historical names of particular places - mostly quantitative data), and information not obtained directly from the map (knowledge of place or conditions - qualitative data). This corresponds to Longley 
et al.'s (2011) data - information - knowledge - wisdom framework. In this paper, the term "quantitative data" relates to the "data - information" part of the framework, and "qualitative data" or "local knowledge" corresponds to "knowledge - wisdom".

For the analysis of the contents of the old map, a method of crowdsourcing was chosen, and the project called "Stories of Places" (which lasted from October to November 2015) was prepared. "Stories of Places" was funded by the Technical University of Liberec through a grant aimed at assessing the possibilities of involving the public into studying of old maps. The goal of the project was to verify whether "non-professional scientists" are able to be "more than just a tool" for gathering a large amount of data from an old map.

\section{Related work}

As the project was based on the participation of a large group of volunteers and its aim was to collect data and information, it could be termed 'crowdsourcing', defined by Howe (2006) as a practice combining two concepts: the crowd and outsourcing. Crowdsourcing can thus be described as the process during which an institution or a company asks a large number of people, in the form of an open call, for assistance with gathering data or services (Howe, 2006). According to Goodchild \& Glennon (2010), crowdsourcing is based on the assumption that a group of people might present a more efficient tool for solving a particular problem than specialists in a given field, and that the results should be closer to the truth ("many heads are better than one").

The analysis of old maps is usually the domain of experts such as historians or urban planners, and therefore it could be considered a type of scientific work. In distributing scientific work to volunteers, to non-professional scientists, we refer to 'citizen science' (Silvertown, 2009). The concept is not new: as Cohn (2008) illustrates, the National Audubon Society's Annual Christmas Bird Count in 1900, which aimed at counting the bird population by amateur ornithologists, was an early example of citizen science.

Because most of the information obtained by non-experts from the old map that was used is spatial, we can also refer to "volunteered geographic information" or VGI (Brown \& Kyttä, 2014). The term was coined by Goodchild in 2007 as a special case of user-generated content, closely related to citizen science and crowdsourcing. There are numerous examples of VGI projects - Wikimapia, OpenStreetMap (Goodchild, 2007) or Na ovoce ("For Fruits" - http://na-ovoce.cz/en/our-team, which maps fruit available for free in the Czech Republic).

All three methods1 produce a large amount of data in a short time through the collaboration of non-experts, and as such the data should be validated. Several studies on credibility and spatial accuracy of VGI have already been carried out (e.g. Flanagin \& Metzger, 2008; Haklay, 2010). Rak (2013) describes two basic approaches used for quality control. The "authoritative" approach was used, for instance, to assess the geometrical quality of

\footnotetext{
${ }^{1}$ In this paper, the author uses the term crowdsourcing because he considers it to be the most general.
} 
OpenStreetMap data (Haklay, 2010) - in this study, OSM data were compared with traditional datasets (Ordnance Survey data for the United Kingdom). As for the second approach, called "crowdsourcing methods" by the author, volunteers themselves validate the data and are thus involved in the process of self-validation.

We find several examples of crowdsourcing projects focused on history and old maps, such as StaréMapy.cz ("Old Maps" - www.staremapy.cz, available only in Czech). The project aims to catalogue old maps gathered from different map collections in the Czech Republic on the basis of the geo-referencing method (adding coordinates to the metadata). In this project, no special skills are required on the part of the participants: they only need to know how to work with a map (matching at least four places on old and current maps). From 2013 to 2016, users geo-referenced more than 30,000 old maps (StaréMapy.cz, 2016). It would have been impossible to achieve such results without involving the public.

Another similar project is called eHarta (Crăciunescu et al., 2011), aimed at creating a collection of old Romanian maps, in which volunteers geo-reference old maps or create metadata for them.

The closest project to the present research is Maphub (Haslhofer et al., 2013), a project in which volunteers can geo-reference old maps and add comments related to the places on the map. However, the main focus of Maphub is semantic tagging; old maps and knowledge from volunteers are used only for testing purposes.

\section{Area Studied}

The area studied is located mostly in the Liberec Region, in northern Bohemia, in the Czech Republic, and partly in Germany and present-day Poland (Figure 1). It covers the area from the Lusatian Mountains in the west to the Giant Mountains in the east. The border region was known as the Sudetenland (in German) in the first half of the 20th century as the majority nationality in the area was German until 1945.

There have been two major changes in the population structure of the area in recent history, both of which were political in origin. In 1938, part of the Czech population had to leave as a result of the Munich Agreement, under which the Sudetenland was annexed to Germany. In 1945, the German population of the area was displaced after Germany was defeated in the Second World War. According to Andrejsová (2009), the city of Liberec had about 74,000 inhabitants of German nationality in 1945, compared to 3,000 in 1948. The number of inhabitants of Czech nationality grew from approximately 6,000 in 1945 to around 52,000 in 1948.

These changes led to much local knowledge being lost. People left their homes, buildings lost their purposes and local place names their meanings. Recently, there have been many publications focused on local history of the region. You can find about thirty publications dealing with the history of the Liberec Region in any local bookshop. In Liberec, there are two associations dedicated to discovering forgotten historical information and raising public awareness, which shows how topical and useful the project is. 


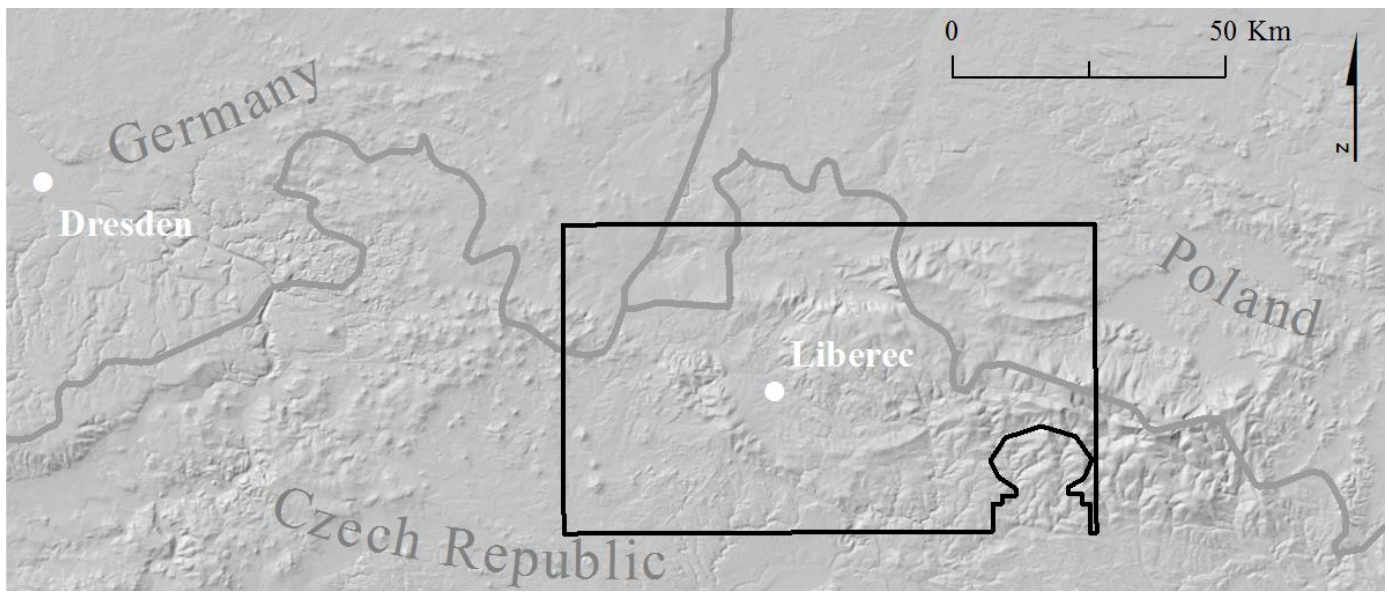

Figure 1: Location of the area studied. Cut-out in the lower-right corner marks the place where the heading and map legend are situated on the old map.

\section{Methods}

\section{Old map used}

As Semotanová (2001: 13) states, the definition of an old map is necessarily relative and subjective: "Any map created more than a hundred years ago can definitely be considered an old one. However, from a different point of view, a map created prior to any changes in the area it displays could also be considered an old map (with outdated content)." This definition can be applied to all maps of the region studied that were created before the Second World War, such as the one used for this study, Matouschek's Spezialkarte vom Jeschken- und Isergebirge map (published in 1927). Another reason for using this map is its detailed content and the cartographer's method of collecting names. Matouschek (1927) says that he created the map based on his own research and corrected the place names by collaborating with people who actually lived in the region. It can thus be assumed that the geographical names used in the map are those that people really used. Moreover, it also enables us to determine the border between the German- and Czech-speaking areas on the map.

The original of the Spezialkarte vom Jeschken- und Isergebirge map has a scale of 1: 50000 and measures $1270 \times 720 \mathrm{~mm}$. It covers the area from the Lusatian Mountains in the east to the western part of the Giant Mountains. It focuses on tourist information, such as hiking trails and places of interest. The map was distributed in two versions, which differed in the materials used: a seamless paper version, and a more resilient version divided into 44 sections and attached to linen. The map was published in an edition of 10,000 by Verlages Gebrüder Stiepel in Reichenberg (Stiepel Brothers publishing house in Liberec). The linen map, shown in Figure 2, was used in the project. 


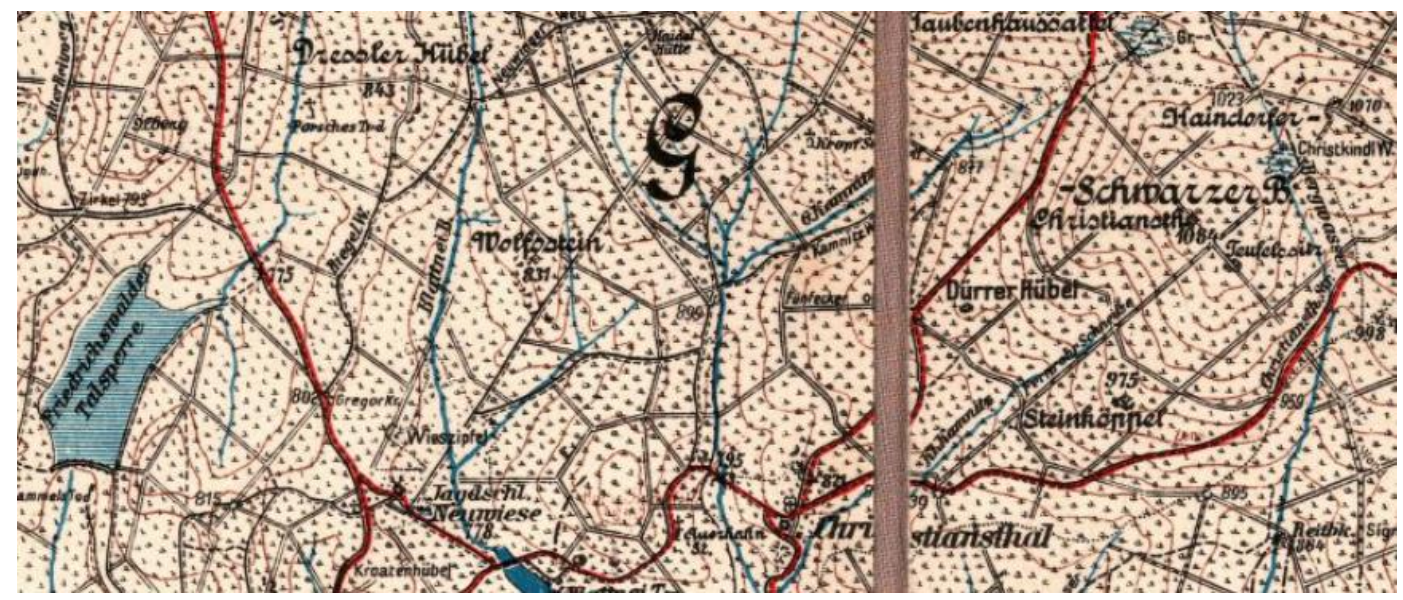

Figure 2: Part of the Spezialkarte vom Jeschken- und Isergebirge map (1927). The vertical brown line is the seam between two sections.

\section{Topic}

As peaks displayed on a map can be considered both quantitative and qualitative data, they were chosen as a suitable topic; additionally, they are easy to find on a map due to their map symbol. Geo-referencing may be inaccurate as a result of several well-known factors associated with old maps, such as unequal wear and tear of the paper over time, or inaccuracies in the original map content. Pairs of coordinates (from an old map and from a current map) and other attributes (historical and current names, the elevation of the peaks) were therefore collected in the project. Current information was taken from OpenTopoMap and the Czech State Map (updated in 2013). All this information was labelled as quantitative data. The collected qualitative data included information about the peaks (about their location, history and name changes).

\section{Definition of the target group and publicity}

For the purpose of collecting quantitative data, volunteers do not have to be from the region studied because the activity does not require any special skills apart from the ability to work with a web application and to recognize peaks on an old map. However, the situation is much more complicated when collecting qualitative data, because volunteers should be at least interested in the history of the given place or in the topic studied, and they should also have some kind of relationship to the region or live there. It could also be assumed that older people might have more knowledge of local history because they are more likely to have lived in the region for a longer period of time. This could be a limiting factor in choosing the appropriate participatory method because older people might have difficulties working with the web application.

The public from the region studied were informed about the open call through several different media: a request for sharing information was posted on Facebook; there were advertisements on the official site of the city of Liberec and its tourist website; similar 
advertisements were also published in printed media, such as the city's newspaper, and posters were distributed in public spaces. In addition, local volunteers involved in the maintenance and conservation of the heritage of Liberac, who have a deep knowledge of the region's history, were contacted thanks to personal relations. In order to reach members of the public interested in historical or spatial studies, advertisements were also placed on geographic and GIS websites based in the region studied.

In addition, a contest was announced to raise interest in the project. All volunteers registered from October to December 2015 had a chance to compete in two categories. The first was for the highest number of peaks added. The second was for the most popular comment. As a means of motivation, the first two places won prizes, such as an old map facsimile or some other smaller prize.

\section{Validation}

The quality control of the data collected in the project was carried out on two levels. The first level was the verification of attributes against a given set of rules, used for technical validation of the data, i.e. to ensure that all necessary attributes were filled in or that all attributes were in the right format. It proved difficult to define the attributes required in the project because several possibilities (and combinations of them) were at play:

- a peak had name and elevation on the old map,

- a peak had name or elevation on the old map,

- a peak had name and elevation on the current map,

- a peak had name or elevation on the current map,

- a peak had neither name nor elevation on the current map (it was not displayed).

If a peak was not displayed on the current map, this might have been a mistake on the current map (in the case of OpenTopoMap, this might have been caused by the way it was created - see e.g. Haklay, 2010), or it might indicate a change in the perception of the importance of the peak by the people who create current maps (in the case of the Czech State Map).

Having considered the options listed above, only the coordinates of a peak and its name or elevation on the old map were defined as necessary attributes. The volunteers could also add an associated story (optional), but in that case they had to state the source of the information, and if it was anything other than common knowledge, they had to reference the source.

The second level of quality control was for the content. It was validated by crowdsourcing (Rak, 2013). All volunteers could give validation points to entries added by others. If they agreed with a story, they could vote for it; if not, they could give it a low ranking. In order to prevent deliberate unjustified low ranking, volunteers had to describe the mistake they found. In addition, they could not validate their own inputs or vote more than once for a given entry. 


\section{Technical solution}

Based on research and due to the limitations of existing solutions, 2 a web map application was created for the purposes of the project. It first gave a brief introduction to the project, its topic, aims, methods and outputs. An important part of the whole project was the abovementioned contest. The volunteers had to be registered in order to participate in the project. The application was built on Bootstrap library, Leaflet, GeoServer and PostgreSQL.

The user interface of the map application was made as user-friendly as possible. The window with the map was made as large as possible to allow easy and intuitive manipulation with the map, using a standardized layout (Figure 3).

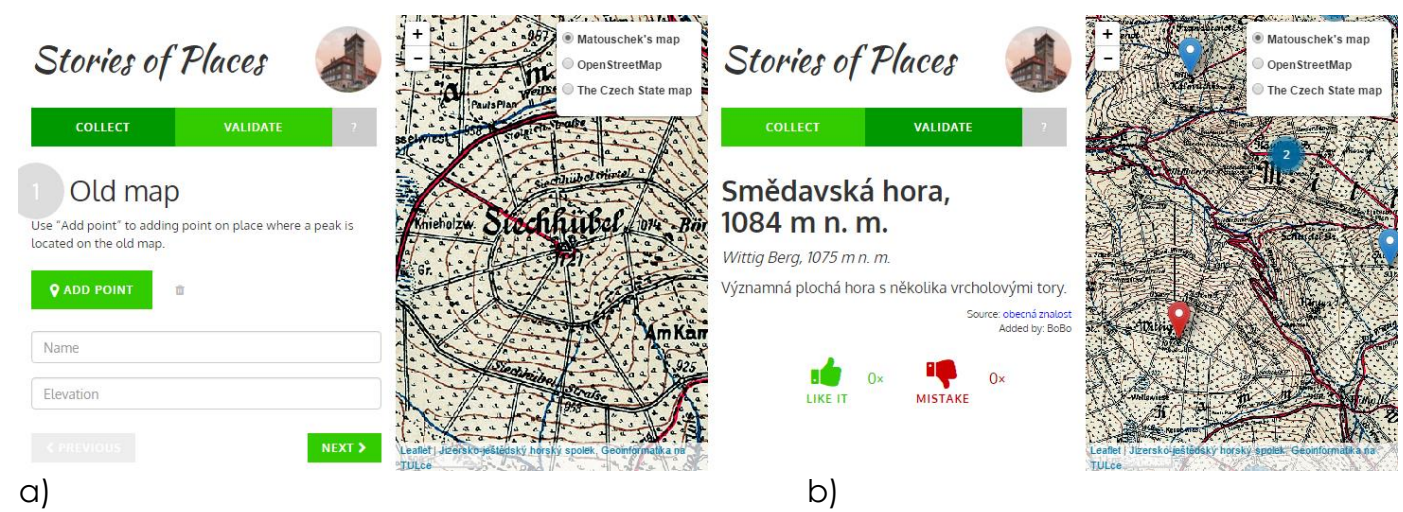

Figure 3: Layout of the map application. a) interface for adding a new point; b) interface for validation of existing points. A demo version is available at: http://mapy.fp.tul.cz/pribehymist/demo.

Volunteers had to choose whether they wanted to add a new point or validate already existing data. The process of adding new information was clearly described (Figure 4).

\footnotetext{
${ }^{2}$ For most solutions considered, it was impossible to use both, the old and current maps as a background map (Ushahidi), or to use a pre-built web application combining collecting and browsing data as a registered volunteer (ArcGIS Online). Some other solutions have serious limitations in their free versions (CartoDB, Mapbox) or they require a large amount of programming.
} 


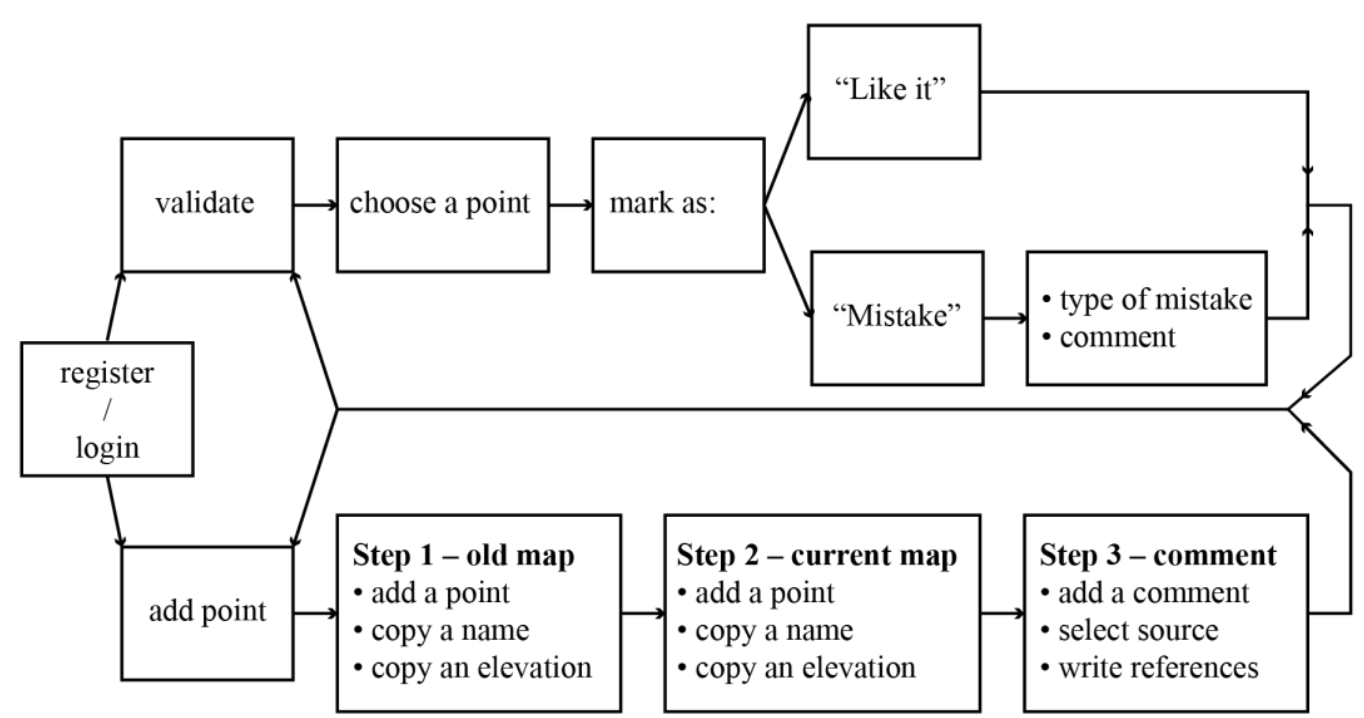

Figure 4: Process of adding/validating data.

\section{$5 \quad$ Results}

\section{Volunteers}

In total, 19 volunteers registered between 10 October and 31 December 2015, mostly from the region studied. Two volunteers had their permanent residence outside the region. See the Table 1 for statistical information about the users:

Table 1: Statistical information about the 19 registered users in the contest.

\begin{tabular}{|c|c|c|c|}
\hline Gender & Age & Education level & $\begin{array}{l}\text { Number of years spent in } \\
\text { the area studied }\end{array}$ \\
\hline Male - $13(68 \%)$ & $20-30$ yrs. old $-5(26 \%)$ & $\begin{array}{l}\text { Sec. school }-8 \\
(42 \%)\end{array}$ & $11-15$ years $-2(11 \%)$ \\
\hline \multirow[t]{4}{*}{ Female $-6(32 \%)$} & 31-40 yrs. old $-7(37 \%)$ & \multirow{4}{*}{$\begin{array}{l}\text { University - } 11 \\
(58 \%)\end{array}$} & $15+$ yrs. $-16(84 \%)$ \\
\hline & $41-50$ yrs. old $-3(16 \%)$ & & Outside of region $-1(5 \%)$ \\
\hline & $51-60$ yrs. old $-3(16 \%)$ & & \\
\hline & $71-80$ yrs. old $-1(5 \%)$ & & \\
\hline
\end{tabular}


In terms of age, the two largest categories consisted of volunteers between the ages of 20 and $40(63 \%$ in total). This could be due to the media used to inform the public about the project, corresponding to the distribution of age categories on Facebook (Statista, 2016), where most advertisements were posted. Only 9 volunteers from 19 registered were active participants, i.e. added new points or validated already existing points; 5 of them added at least one point and voted for at least one existing point, i.e. validated the point; 3 of them only added points; 1 of them validated a previously added point.

Deliberate targeting of volunteers from the region was reflected in the number of volunteers with a strong relationship to the region. More than $80 \%$ of the volunteers had lived in the region for more than 16 years and resided in the region permanently. We can therefore assume that they possessed considerable local knowledge.

\section{Collected information and its validation}

In total, 167 points were collected. Most of them were localized in the Czech Republic, even though the map also covers parts of present-day Poland and Germany. Three major areas of points marked can be identified (see Figure 5), based on clusters created by the Kernel Density tool in ArcGIS 10.3. They correspond to the main tourist regions and to the distribution of peaks displayed on the old map used in the study.

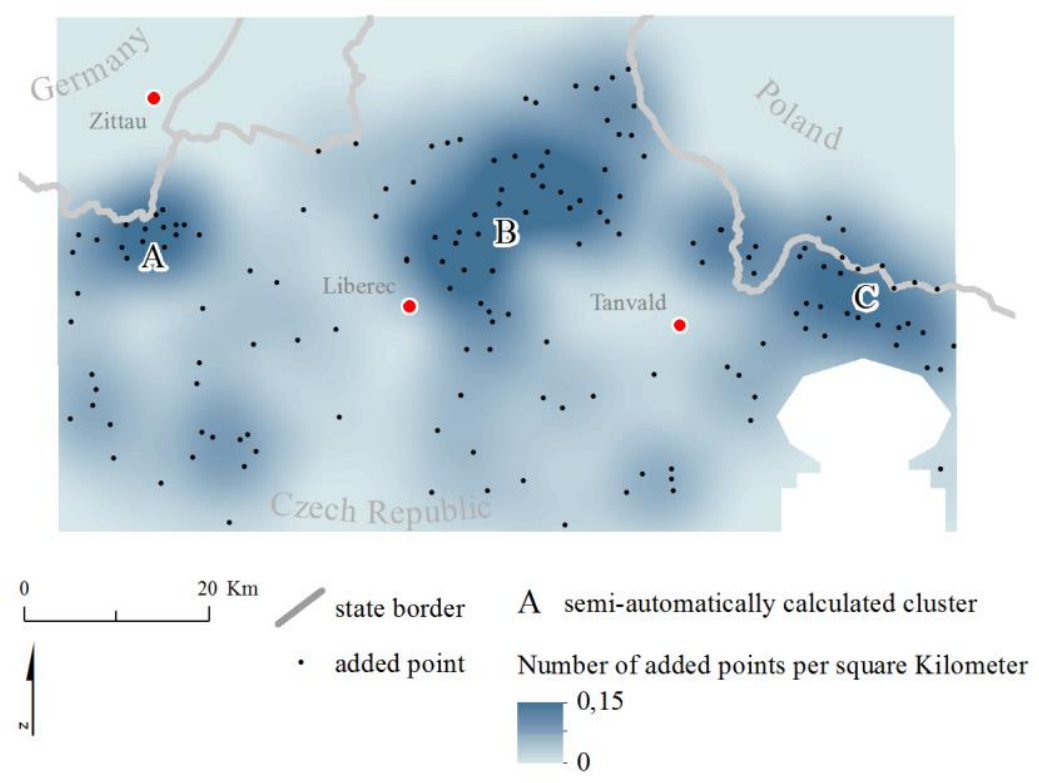

Figure 5: Spatial distribution of collected points.

In total, 92 points (55\%) included comments. These points are especially interesting as they have an added value in the form of the volunteers' local knowledge or their research on the internet or of literature and archives. Sources of information are shown in Figure 6. As the category "others" contains mostly a combination of all four types of information source 
(volunteers cite multiple sources), points from this category were added to the remaining categories. As for the 4\% of points termed "personal research" (done by the volunteer), it was not possible to decide to which category these points belonged.

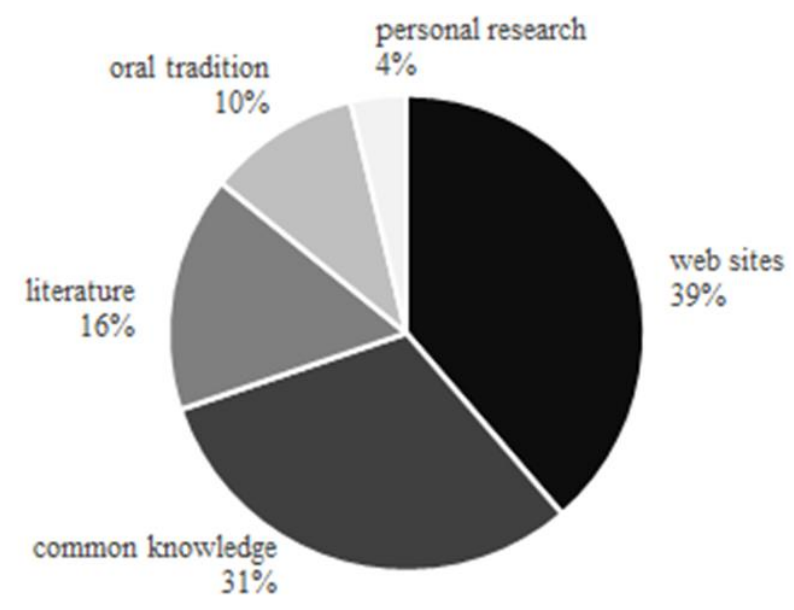

Figure 6: Graph showing the percentage of different sources of information given in comments (92 comments in total).

Websites were the most-cited source of comments (39\%) of comments). The reason might be that searching on the internet is much easier than looking into other sources of information. Comments based on "common knowledge" contain very different information, including descriptions of the place from today's perspective ("There is a breathtaking view of the south and the west of the Jizera Mountains from the top of the rock."), comparisons with other maps or literature, which could also be placed into different categories ("The name "Kameník" is also used on other maps of the region.") or "pure" common knowledge ("Wolf stones are usually placed in memory of a killed wolf."). The main problem with evaluating this category is the difficulty in defining parameters for what is still common knowledge and what is not (Monderer \& Samet, 1989).

As for validating previously added points, there were 112 validations in total. 11 validations were marked as "Like it" (the "favourite" comment had only two votes). 101 validations were marked as "Mistake". The problem with $50 \%$ of them was the absence of a comment, but that in fact was not a mistake because volunteers did not have to write any comment. Other mistakes included typos, missing points, untruthful comments.

\section{Collected data in relation with volunteers}

The graph in Figure 6 shows the number of added peaks per volunteer. The numbers are indicative of participatory projects in general: only a few users create a major part of the data (Haklay, 2013; StareMapy.cz, 2016). In the case of the "Stories of Places" project, two volunteers were responsible for $71 \%$ of all the collected data. 
The knowledge collected should be evaluated on two levels - the correctness of the stories, and the number of stories. The correctness of added information should be checked against other historical documents, earlier research or its sources (i.e. literature or webpages). As simplification for the purpose of this paper, evaluation of the knowledge focused only on the number of added peaks with a comment (number of stories).

The graph in Figure 6 shows the big disproportion between peaks with and without comments added by the first volunteer. He added more peaks than any other volunteer, but only $31 \%$ of the peaks added by him included a comment.

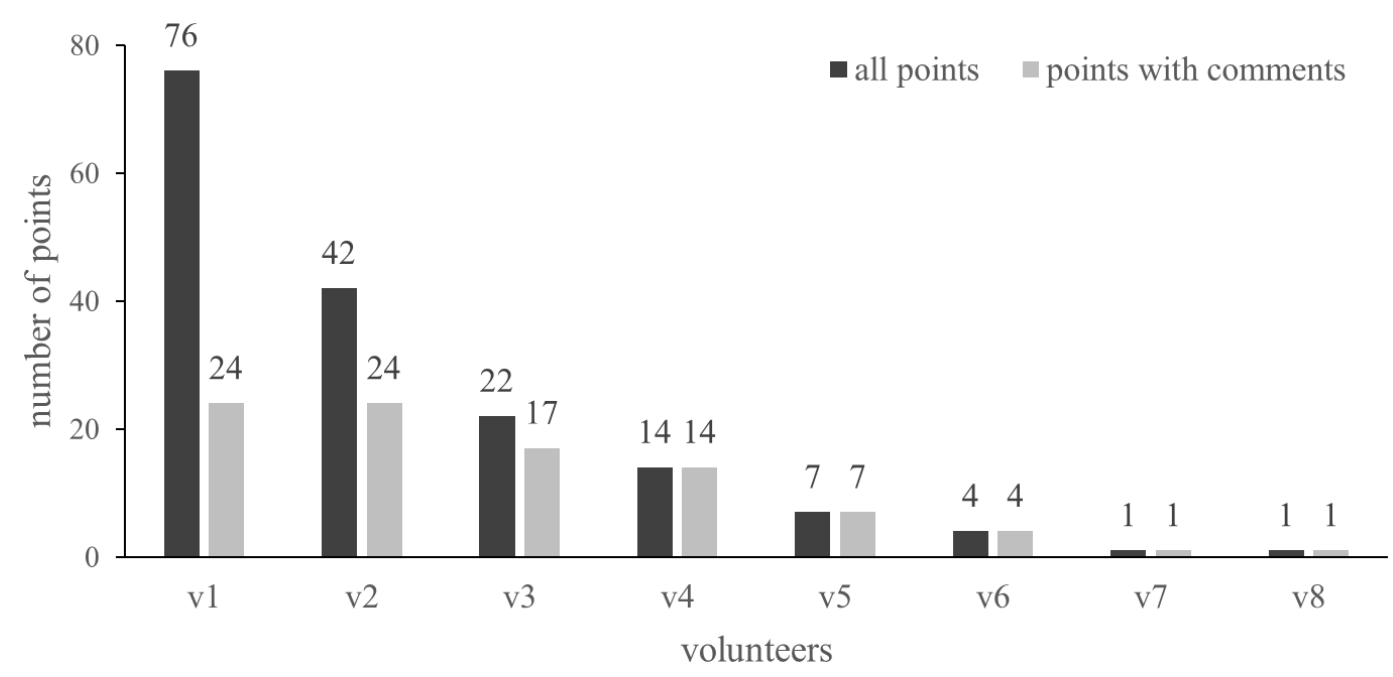

Figure 7: Number of points added by volunteers.

Interesting results were found in the spatial distribution of the points added by the volunteers. However, generally applicable results cannot be drawn from the project in this case because there were not enough volunteers and points added. The following information should therefore be verified by further studies.

Figure 8 shows two volunteers. Volunteer A was from outside the region and most of the points added by him were information from maps or information copied directly from Wikipedia. He did not validate any other added points. The spatial distribution of points added by him covered the entire region studied. Volunteer B was from the region and he commented on all points that he added and also validated the work of others. His work was localized in a relatively small area near his place of residence. We find similar behaviour among the rest of the participants - i.e. differences between those who live in the region and those who do not. 


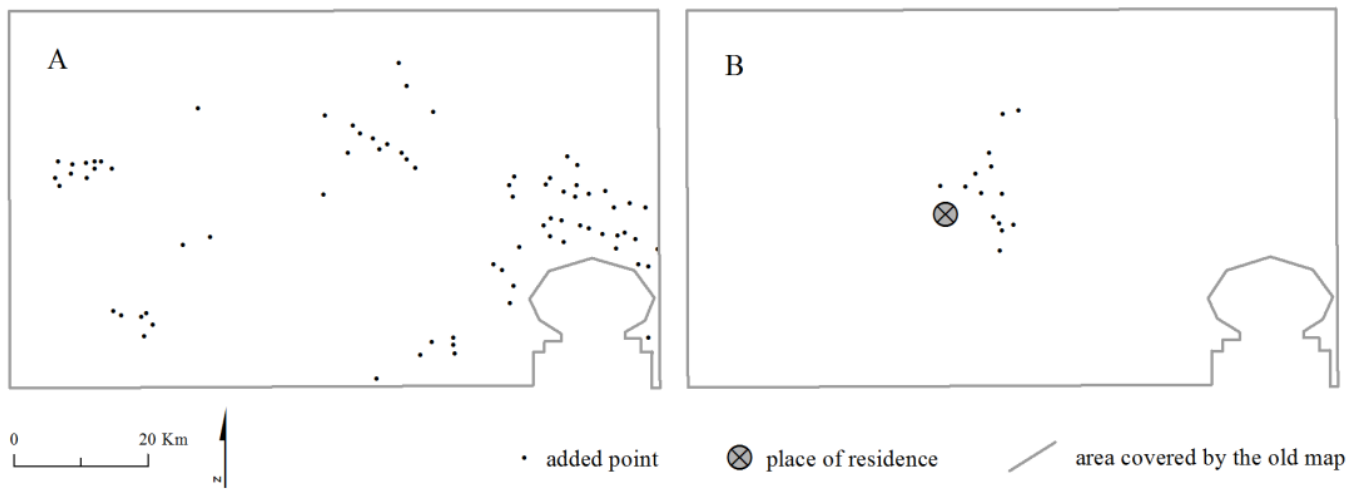

Figure 8: Spatial distribution of points added by selected volunteers. Volunteer A lives outside the region; Volunteer $\mathrm{B}$ in the region.

\section{Conclusion and Discussion}

The present paper describes the project "Stories of Places". The project focused on gathering information from the public on peaks, their former and current names, elevation and history, using an old map. A web map application was used as the basic method, and a contest was announced to motivate people to take part in the project. In total, 19 volunteers registered on the project's website from 12 October to 31 December, 9 of whom were active participants. They added 167 points, 92 of which contained additional information, such as the history of the place, its name, etc. It is important to note that the map application presented in this paper served only as a technical solution and was not a key part of the project, even though it had a certain impact on the project's results. The map application was simply a tool for carrying out research based wholly on volunteer work with old maps and their analysis.

The data collected from "Stories of Places" could be used in several ways. Pairs of coordinates could be used for more accurate geo-referencing of old maps or as a basis for the vectorized content of the old map used. The database of old and current names is interesting for linguistics experts for the study toponyms in this region where extensive renaming took place after the Second World War. And the stories are valuable for anyone who is interested in the history of the region and who wants to know more about the place where he or she lives. In general, these stories could help to rebuild local knowledge that has been lost.

Based on the number of participants, one might think that the public was not very interested in the project, and one possible explanation could be insufficient publicity, but the analysis of the dedicated website by Google Analytics tools shows that over 700 people visited the main page of the website in the course of the contest. In view of the size of the region studied, the number of visitors to the main page does indicate noteworthy public interest. This was also confirmed by the feedback from the volunteers involved. They said that their motivation to participate in the project was the topic chosen. However, the technical solution selected might not have been optimal for people who do not have much experience working with 
web applications, which may have accounted for the relatively low participation rate. Finally, the complexity of the information being collected could have been another limiting factor as well.

In several cases, it was apparent that people living in the region added points close to their places of residence, and their contributions consisted largely of comments added to particular points. These people also served as validation tools. Points added by volunteers from outside the region covered a much larger area and contained fewer comments, or their comments contained information mostly accessible online. Such results were to be expected, but in the case of this particular project, they cannot be considered generally valid due to the small number of volunteers, and added points and should therefore be confirmed by further research.

The results of the project also show that the public can be used for extracting information from old maps, both as a "tool for fast extraction of quantitative data" and as a source of qualitative data. This method is widely used in development and environmental projects but less so for analysing old maps, where crowdsourcing is used mostly for processing large amounts of data (e.g. projects Georeferencer.org, eHarta). As for focusing on old maps and local knowledge, only a few similar attempts have been made, such as the project Maphub. Interestingly, the results of all these projects suggest that the public is willing to participate in projects involving work with old maps, even if it means that they have to do their own research. This was confirmed by one of the volunteers, who said: "Everybody should know about the history of the place they live in. And this type of project forces people to find new and more detailed information about their neighbourhood."

However, the success of similar projects depends on many other factors apart from people's willingness to participate, such as advertising, motivation, topic, ability to participate, etc. Future studies should therefore focus on the following question: "What should we do to attract more volunteers and thus gain more generally applicable results?" This question should be addressed by studies concerned with a different map, topic, method of participation and area of study.

To conclude, the main motivation for participating in this project was its topic, and the public can indeed be used for extracting information from old maps. Another conclusion which can be drawn is that people from the region studied add points close to their place of residence and add more qualitative information compared to people from outside the region in question, but this result must be confirmed by further research. The technical solution of crowdsourcing selected here is a suitable method for this type of research, but it could be improved by adding information gathered in person (workshops, guided interviews, etc.).

\section{Acknowledgments}

The project "Stories of Places" was funded by, and this article was written as a part of, a student grant competition at the Technical University of Liberec. [This individual project was part of the project "Neocartography methods for studying old maps", grant number: 21106]. 


\section{References}

Andrejsová, J. (2009). Kulturní život v Liberci po druhé světové válce (Diploma thesis, Faculty of Philosophy, University of Pardubice).

Brown, G. \& Kyttä, M. (2014). Key issues and research priorities for public participation GIS (PPGIS): A synthesis based on empirical research. Applied Geography, 46, pp. 122-136.

Brůna, V., Pacina, J., \& Vajsová, E. (2014). Modelling the extinct landscape and settlement for preservation of cultural heritage. Città e Storia, 9(1), pp. 131-153.

Cohn, J. P. (2008). Citizen science: Can volunteers do real research? Bioscience, 58(3), pp. 192-197.

Cousins, S. A. (2001). Analysis of land-cover transitions based on 17th and 18th century cadastral maps and aerial photographs. Landscape Ecology, 16(1), pp. 41-54.

Crăciunescu, V., Constantinescu, Ş., Ovejanu, I., \& Rus, I. (2011). Project eHarta: a collaborative initiative to digitally preserve and freely share old cartographic documents in Romania. ePerimetron, 6(4), pp. 261-269.

Domaas, S. T. (2007). The reconstruction of past patterns of tilled fields from historical cadastral maps using GIS. Landscape research, 32(1), pp. 23-43.

Flanagin, A. J. \& Metzger, M. J. (2008), The credibility of volunteered geographic information. GeoJournal, 72, pp. 137-148.

Goodchild, M. (2007). Citizens as sensors: The world of volunteered geography. GeoJournal, 69, pp. 211-221.

Goodchild, M. \& Glennon, A. (2010). Crowdsourcing geographic information for disaster response: a research frontier. International Journal of Digital Earth, 3(3), pp. 231-241

Haklay, M. (2010). How good is volunteered geographical information? A comparative study of OpenStreetMap and Ordnance Survey datasets. Environment and planning B, Planning \& design, 37(4), pp. 682-703.

Haklay, M. (2013). Citizen Science and Volunteered Geographic Information: Overview and typology of participation, in: Sui, D., Elwood, S., Goodchild, M. (eds). Crowdsourcing Geographic Knowledge. Volunteered Geographic Information (VGI) in Theory and Practice, Berlin: Springer (pp. 105-122).

Haslhofer, B., Robitza, W., Lagoze C., \& Guimbretiere, F. (2013). Semantic tagging on historical maps. In Proceedings of the 5th Annual ACM Web Science Conference (WebSci '13) (pp. 148157).

Howe, J. (2006). Crowdsourcing: A definition http://crowdsourcing.typepad.com/cs/2006/06/crowdsourcing_a.html [Accessed May 2016].

Longley, P. A., Goodchild, M. F., Maguire, D. J., \& Rhind, D. W. (2011). Geographic Information Systems and Science. Oxford: Wiley.

Matouschek, J. (1927). Begleitworte zur neuen Gebirgsvereinskarte. In Jahrbuch des Deutschen Gebirgsvereines für das Jeschken- und Isergebirge, 37 (pp. 201-203).

Monderer, D. \& Samet, D. (1989). Approximating common knowledge with common beliefs. Games and Economic Behavior, 1(2), pp. 170-190.

Rak, A. (2013). Legal Issues and Validation of Volunteered Geographic Information (Doctoral dissertation, Department of Geodesy and Geomatics Engineering University of New Brunswick).

Semotanová, E. (2001). Mapy Čech, Moravy a Slezska v zrcadle staletí. Praha: Libri.

Silvertown, J. (2009). A new dawn for citizen science. Trends in Ecology and Evolution, 24(9), pp. 467-471.

StaréMapy.cz (2016), Celkové výsledky od počátku projektu. http://www.staremapy.cz/vysledky/\#celkove-vysledky [accessed 10 May 2016]

Statista (2016, January 16). Facebook user age distribution worldwide 2014. http://www.statista.com/statistics/376128/facebook-global-user-age-distribution/ [accessed 16 January 2016] 